Pires, P.S.; Welter, B.M.. Tipologia dos atrativos naturais nos destinos de turismo na natureza no Brasil e identificação dos seus componentes biofísicos, através do modelo de composição visual da paisagem. Anais do VIII Congresso Nacional de Ecoturismo e do IV Encontro Interdisciplinar de Ecoturismo em Unidades de Conservação. Revista Brasileira de Ecoturismo, São Paulo, v.4, n.4, 2011 , p. 529.

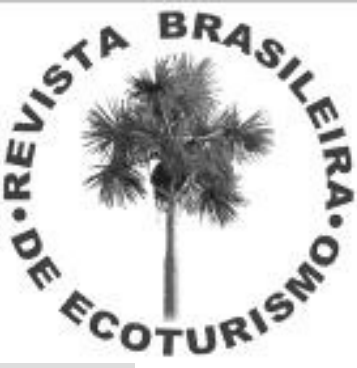

\title{
TIPOLOGIA DOS ATRATIVOS NATURAIS NOS DESTINOS DE TURISMO NA NATUREZA NO BRASIL E IDENTIFICAÇÃO DOS SEUS COMPONENTES BIOFÍSICOS, ATRAVÉS DO MODELO DE COMPOSIÇÃO VISUAL DA PAISAGEM
}

\author{
Paulo dos Santos Pires*, Beatiz Moscheta Welter** \\ *Universidade do Vale do Itajaí, **Hotel Emiliano \\ E-mails: pires@univali.br, beatrizwelter@yahoo.com
}

O turismo na natureza e no seu bojo o ecoturismo, enquanto paradigma de sustentabilidade, desde meados da década de 1990 tornaram-se pujantes segmentos do turismo tanto em nível mundial como no Brasil, país que com sua notável biodiversidade e profusão de ecossistemas, desponta neste cenário com uma amplitude de recursos e paisagens naturais de reconhecido potencial para suprir a crescente demanda doméstica e internacional voltada para estes segmentos. A constatação deste potencial se assenta em uma base ecológica constituída por sete grandes ecossistemas, os Biomas, além das áreas de transição entre eles. Já em escala regional, os Biomas podem ser reconhecidos em 49 Ecorregiões, cuja escala de mapeamento favorece o planejamento regional do turismo. Por outro lado, percebe-se que em escala mais localizada, ao nível dos destinos, ainda não há uma referência de sistematização das informações sobre os atrativos naturais e suas respectivas paisagens, plenamente aceita e utilizada especialmente na operacionalização do turismo em áreas naturais. É neste contexto o artigo trata da tipologia dos recursos naturais e atrativos relacionados nos destinos de turismo na natureza no Brasil, com ênfase na identificação dos seus componentes biofísicos. Para tanto, realizou-se uma abordagem, sobretudo, qualitativa, complementada por tratamento quantitativo, utilizando-se dados de natureza primária que foram coletados junto a diversas fontes de informação disponíveis, referentes a uma amostra não probabilística de 56 operadoras atuantes no segmento do turismo na natureza e do ecoturismo, com sede na Grande São Paulo, Brasília e capitais dos Estados do Rio Grande do Sul, Paraná, Minas Gerais, Rio de Janeiro e Bahia. Para o processamento e sistematização destes dados, adotaram-se dois modelos, sendo um de composição visual das paisagens e outro de classificação dos atrativos turísticos. A análise de conteúdo dos dados compilados e sistematizados resultou, primeiramente, em uma proposta de identificação e descrição dos componentes naturais dos destinos de turismo na natureza com base na composição visual de suas paisagens, exemplificada em três destinos preferenciais deste segmento. Em seguida, apresenta-se um quadro síntese da tipologia dos recursos naturais e atrativos correspondentes, associados aos respectivos Biomas, com maior ocorrência nos 45 destinos identificados como os de maior oferta nestes segmentos de mercado e, portanto, com representatividade nacional. Com isso, acredita-se que além de uma possível contribuição metodológica para a pesquisa acadêmica em turismo, a forma de ordenamento das informações relativas aos destinos e seus atrativos naturais, quando orientada por critérios de composição visual da paisagem e relacionada à uma base ecológica, poderá proporcionar uma melhor padronização e correta descrição da "matéria prima" do produto turístico ofertado pelas agências e operadoras, com reflexos positivos na qualidade e competitividade de seus produtos.

Palavras-chave: Atrativos naturais; Turismo na natureza; Paisagem. 